\title{
Hepatitis B Vaccination Coverage among Health Workers in a University Hospital in Northern Cyprus*
}

\author{
Emine Unal Evren' (D, Hakan Evren' (D), Emrah Guler² ${ }^{2}$, Kaya Suer ${ }^{3}$ (D) \\ 'Department of Clinical Microbiology and Infectious Diseases, University of Kyrenia Faculty of Medicine, Kyrenia, Cyprus \\ ${ }^{2}$ Department of Microbiology and Clinical Microbiology, Near East University Faculty of Medicine, Nicosia, Cyprus \\ ${ }^{3}$ Department of Clinical Microbiology and Infectious Diseases, Near East University Faculty of Medicine, Nicosia, Cyprus \\ ORCID iDs of the authors: E.U.E 0000-000I-9455-0473; H.E. 0000-000I-8247-8I44; E.G. 0000-0002-I635-005I; K.S. 0000-0002-2565- \\ 3425.
}

Cite this article as: Evren EU, Evren H, Guler E, Suer K. Hepatitis B Vaccination Coverage among Health Workers in a University Hospital in Northern Cyprus. Cyprus J Med Sci. 2021; 6(3): 234-236.

BACKGROUND/AIMS

This study aimed to evaluate the hepatitis B vaccination coverage rates among health care workers (HCWs) in a university hospital in Northern Cyprus.

\section{MATERIAL and METHODS}

Our sample consists of $486 \mathrm{HCWs}$. The study was performed retrospectively on a group of $486 \mathrm{HCWs}$, whose blood serum samples were evaluated in the microbiology laboratory of the hospital. Laboratory tests were conducted for identification of $\mathrm{HBs} A g$ and antiHBs. Those who were HBsAg positive were excluded. All the data of the participants were obtained from the hospital system, and the data were analyzed using the Statistical Package for the Social Sciences 15.0 software package (SPSS Inc., Chicago, IL, USA).

\section{RESULTS}

Four of the $486 \mathrm{HCWs}$ were HBsAg positive and excluded from the study. From the $482 \mathrm{HCWs}$ in the study group, II3 (23.4\%) of whom were male, and $369(76.6 \%)$ of whom were female, altogether had an average age of 36.1I \pm 11.25 (20-7lyears). Among them, 270 (56\%) were nurses, 93 (19.3\%) were technicians, $77(16 \%)$ were cleaning personnel, and $42(8.7 \%)$ were doctors. It was found that 375 ( $77.8 \%)$ $\mathrm{HCWs}$ were anti-HBs positive and $107(22.2 \%)$ were negative in the current study. Statistically, physicians, nurses, and technicians were found to be immune to hepatitis B virus significantly compared to other hospital workers $(P<.05 ; P<.0001)$.

\section{CONCLUSION}

The current vaccination coverage among HCWs at university hospital is as high as in developed countries. Despite a high level of acceptance, nearly one-fifth of the HCW's remains vulnerable to the infection. Efforts to target the unvaccinated staff should be encouraged.

Keywords: Vaccine, hepatitis B, health care workers, prevention

\section{INTRODUCTION}

Hepatitis B virus (HBV) infection is one of the significant health problems, with an estimated 260 million chronically infected people. The infection accounts for 887,000 deaths annually due to its complications like hepatocellular carcinoma and cirrhosis.' Health care workers (HCWs) are one of the special populations who have particular risks for both acquiring and transmitting HBV infection to patients. ${ }^{2}$ It is reported that HCWs have an up to the fourfold incidence of this infection in the general population. ${ }^{3}$ Direct contact with infectious material, such as infected blood and body fluid, is the leading risk factor to acquire HBV infection for HCWs. Highly infectious HBV can also be transmitted in the absence of visible blood and remains on environmental surfaces for at least seven days. ${ }^{4-6}$ Thus, the infections can occur with no history of apparent exposure. Although most of the HBV infections are attributed to percutaneous exposure, the potential HBV transmission through contact with surfaces has been demonstrated in investigations of outbreaks among patients and staff of hemodialysis units. ${ }^{7,8}$ 
TABLE I. The Distribution of HCWs Anti-HBs Results

\begin{tabular}{|c|c|c|c|}
\hline Anti-Hbs & $\begin{array}{c}\text { Negative } \\
(<10), \mathrm{n}(\%)\end{array}$ & $\begin{array}{l}\text { Positive } \\
(>10), n(\%)\end{array}$ & $\begin{array}{l}\text { Total, } \\
\text { n (\%) }\end{array}$ \\
\hline Doctor & $7(16.7)$ & 35 (83.3) & $42(100)$ \\
\hline Nurse & $37(13.7)$ & $233(86.3)$ & $270(100)$ \\
\hline Technician & $24(25.8)$ & $69(74.2)$ & $93(100)$ \\
\hline Cleaning personnel & $39(50.6)$ & $38(49.4)$ & $77(100)$ \\
\hline Total & $107(22.2)$ & $375(77.8)$ & $482(100)$ \\
\hline
\end{tabular}

A safe and effective HBV vaccine has been available since 1981 and is the crucial strategy to prevent HBV infections.' Although the vaccine is recommended for $\mathrm{HCWs}$ by the $\mathrm{WHO}$, vaccination coverage remains low. ${ }^{10}$

In Northern Cyprus, there are no data available on the vaccination status of HCWs. We, therefore, aimed to estimate the prevalence of hepatitis $B$ vaccination among HCWs at a university hospital in Northern Cyprus.

\section{MATERIAL and METHODS}

The study was performed retrospectively on a group of 486 $\mathrm{HCW}$, whose blood serum samples were evaluated in the microbiology laboratory of the hospital. HBsAg and anti-HBs tests were performed on the samples using the chemiluminescence enzyme immunoassay method (Architect i2000 SR, Abbott, A.B.D.). HBsAg positive staffs were excluded from the study group. The study was conducted by the recommendations of the manufacturer, and $>10 \mathrm{IU} \mathrm{mL} \mathrm{m}^{-1}$ was accepted as a positive result.

All the demographic data of the participants and laboratory results were obtained from the hospital system, and the data were analyzed using the SPSS 15 statistical software (IBM SPSS Corp.; Armonk, NY, USA). Through applying Pearson's chi-squared test and Fisher's exact test, $P<.05$ was accepted as significant. Ethical committee approval was not obtained since the study involved only retrospective data.

\section{RESULTS}

Four of the $486 \mathrm{HCWs}$ were HBsAg positive and excluded from the study. From the 482 hospitals HCWs in the study group, II3 $(23.4 \%)$ of whom were male and $369(76.6 \%)$ of whom were female, altogether had an average age of $36.11 \pm 11.25$ (2071 years). Among them, 270 (56\%) were nurses, 93 (19.3\%) were technicians, 77 (16\%) were cleaning personnel, and $42(8.7 \%)$ were doctors. It was found that $375(77.8 \%)$ HCWs were anti-

\section{Main Points}

- HCWs are at particular risk for both acquiring and transmitting HBV infections.

- Continuous educational programs and initial serological testing of newly recruited staff for HBV can increase vaccine uptake among $\mathrm{HCWs}$

- Despite the high vaccination coverage among HCWs in Northern Cyprus, attention has to be given to nearly one fifth of them who are still susceptible to HBV infections.
HBs positive, and 107 (22.2\%) were negative in the current study.

While $73.5 \%$ of the male HCWs $(n=83)$ and $79.1 \%(n=292)$ of the female HCWs were positive for anti-HBs, the relationship between gender and anti-HBs positivity was not statistically significant $(P=.204) .86 .3 \%(n=233)$ of the nurses, $83.3 \%(n=$ $35)$ of the doctors, $74.2 \%(n=69)$ of the technicians, and $49.4 \%$ $(n=38)$ of the cleaning personnel were found to be positive for anti-HBs (Table I). Statistically, physicians, nurses, and technicians were found to be immune to hepatitis $B$ virus significantly compared to other hospital workers $(P<.0001)$. From among the $375 \mathrm{HCWs}$ who had a positive value for anti-HBs, $24 \%$ ( $n=$ 90) had an anti-HBs value between 10 and 100 , while $76 \%(n=$ 285) were identified to have a value of $>100$.

\section{DISCUSSION}

Hepatitis B vaccine is reported to be one of the safest and effective vaccines according to the international literature." The Advisory Committee on Immunization Practices has been recommending hepatitis B vaccine for HCW since $1982 . .^{10}$ The incidence of acute HBV infection among $\mathrm{HCW}$ s has declined, but the risks for exposure persist. Although the vaccine has been recommended for more than two decades, the coverage rate has remained below the average goal of $90 \% .^{12}$ Suboptimal hepatitis $B$ vaccine coverage is reported to be due to concerns about side effects, lack of availability, and knowledge gaps about the risks of the infection. ${ }^{10}$ These barriers to vaccination suggest that additional education about the safety and benefits of the hepatitis B vaccine may increase acceptance. The $\mathrm{WHO}$ has reported that the vaccination coverage among $\mathrm{HCWs}$ is $18-39 \%$ in low- and middle-income countries and $67-$ $79 \%$ in high-income countries. ${ }^{13,14}$ Some studies showed even lower levels of vaccination coverage. The prevalence of vaccination for HBV among HCWs in Georgia was $12 \%$ similar to that for other developing countries such as Uganda 5\%, Kenya $13 \%$, and Egypt $16 \%$. ${ }^{15}$ These rates are ranging between $50 \%$ and $90 \%$ in Europe.

According to $\mathrm{WHO}$, vaccine coverage among $\mathrm{HCW}$ in the United States is 75 and $77 \%$ in Australia and New Zealand. ${ }^{16,17}$ Our study was in the same line with developed countries with a coverage level of $77.1 \%$. Nurses have the highest level of $85.9 \%$ when compared to other HCWs. Based on previous investigations, raising awareness is the crucial point to vaccination compliance. It is also known that health care personnel viewing their susceptibility to HBV infection as high are more likely to be vaccinated.18,19 This can be possible with proper education programs.

In conclusion, Cyprus is classified as low-intermediate hepatitis $\mathrm{B}$ endemic country with a prevalence of $2-4.9 \%$ by the CDC. ${ }^{20}$ In a comprehensive study, which is reported from Northern Cyprus, the rate of hepatitis B in the population was $1.5 \% .^{21}$ Northern Cyprus has implemented universal hepatitis B vaccination to all infants since 1999. However, nationwide vaccination program for high-risk groups including $\mathrm{HCW}$ s has not been in place. Comparing with the global picture, our vaccination coverage rate is as high as in developed countries. This is a result of continuous educational programs and initial serological testing of newly recruited staff by an infectious disease control team. Despite these efforts, particular attention has to 
be given to nearly one-fifth of HCWs who are still susceptible to $\mathrm{HBV}$ infection.

Ethics Committee Approval: Ethical committee approval was not obtained since the study involved only retrospective data.

Peer-review: Externally peer-reviewed.

Author Contributions: Concept - K.S., E.U.E.; Design - E.U.E., H.E.; Supervision - K.S., E.U.E.; Resources - E.G., H.E.; Materials - E.G., E.U.E.; Data Collection and/or Processing - H.E., E.G.; Analysis and/or Interpretation E.U.E., K.S.; Literature Search - H.E., E.U.E.; Writing Manuscript - E.U.E., E.G.; Critical Review - K.S., H.E.

Conflict of Interest: The authors have no conflicts of interest to declare.

Financial Disclosure: The authors declared that this study has received no financial support.

\section{REFERENCES}

I. WHO. Hepatitis B fact sheet no. 204. Updated. 2017. Available at http://www.who.int/en/news-room/fact-sheets/detail/ hepatitis-b. Accessed August 30, 2017.

2. WHO. Guidelines for the Prevention, Care, and Treatment of Persons with Chronic Hepatitis Infection. Geneva: World Health Organization, 2015

3. Mueller A, Stoetter L, Kalluvya S, et al. Prevalence of hepatitis B virus infection among health care workers in a tertiary hospital in Tanzania. BMC Infect Dis. 2015;15(I):386. [CrossRef]

4. Preboth M. PHS guidelines for management of occupational exposure to HBV, HCV and HIV: Management of occupational blood exposures. Am Fam Phys. 2001;64(12):2012-2014.

5. Bond $W$, Favero $M$, Petersen $N$, et al. Survival of hepatitis $B$ virus after drying and storage for one week. Lancet. 1981;:1550-55I.

6. CDC. Recommendation of the immunization practices advisory committee (ACIP). Inactivated hepatitis B virus vaccine. MMWR Morb Mortal Wkly Rep. 1982;31:327-328.

7. Hennekens $\mathrm{CH}$. Hemodialysis-associated hepatitis: An outbreak among hospital personnel. JAMA. 1973;225(4):407-408. [CrossRef]

8. Garibaldi RA, Forrest JN, Bryan JA, Hanson BF, Dismukes WE. Hemodialysis-associated hepatitis. JAMA. 1973;225(4):384-389. [CrossRef]

9. Aaron D, Nagu TJ, Rwegasha J, Komba E. Hepatitis B vaccination coverage among healthcare workers at national hospital in Tanzania: How much, who and why? BMC Infect Dis. 2017;17(I):786. [CrossRef]
10. Byrd KK, Lu PJ, Murphy TV. Hepatitis B vaccination coverage among health-care personnel in the United States. Public Health Rep. 2013;128(6):498-509. [CrossRef]

II. Saridi M, Toska A, Souliotis K, et al. Vaccination coverage among health care workers in a greek hospital. J Vaccines Vaccine. 20II;2(I23):2.

12. Department of Health and Human Services (US) Proposed healthy people 2020 objectives. 2012. Available at http://www.healthypeople.gov/hp2020/Objectives/TopicAreas.aspx. Accessed February 19, 2017.

13. Prüss-Ustün A, Rapiti E, Hutin Y. Estimation of the global burden of disease attributable to contaminated sharps injuries among healthcare workers. Am J Ind Med. 2005;48(6):482-490. [CrossRef]

14. Tatsilong HOP, Noubiap JJN, Nansseu JRN, et al. Hepatitis B infection awareness, vaccine perceptions and uptake, and serological profile of a group of health care workers in yaoundé, Cameroon. BMC Public Health. 2016;16(I):706. [CrossRef]

15. Topuridze M, Butsashvili M, Kamkamidze G, Kajaia M, Morse D, McNutt LA. Barriers to hepatitis $B$ vaccine coverage among healthcare workers in the republic of Georgia: An international perspective. Infect Control Hosp Epidemiol. 2010;31(2):158-164. [CrossRef]

16. Hutin $Y$, Hauri A, Chiarello L, et al. Best infection control practices for intradermal, subcutaneous, and intramuscular needle injections. Bull World Health Organiz. 2003;81:491-500.

17. Simard EP, Miller JT, George PA, et al. Hepatitis B vaccination coverage levels among healthcare workers in the United States, 20022003. Infect Control Hosp Epidemiol. 2007;28(7):783-790. [CrossRef]

18. Tafuri S, Martinelli D, Caputi G, et al. An audit of vaccination coverage among vaccination service workers in Puglia, Italy. Am J Infect Control. 2009;37(5):414-416. [CrossRef]

19. Suckling RM, Taegtmeyer M, Nguku PM, et al. Susceptibility of healthcare workers in Kenya to hepatitis B: New strategies for facilitating vaccination uptake. J Hosp Infect. 2006;64(3):27I-277. [CrossRef]

20. Schillie $S$, Vellozzi $C$, Reingold A, et al. Prevention of hepatitis B virus infection in the United States: Recommendations of the advisory committee on immunization practices. MMWR Recomm Rep. 2018;67(I):I-3I. [CrossRef]

21. Güler E, Süer K, Arıkan A, Güvenir M, Şanlıdağ T. Seroprevelance of hepatitis $B$ virus, hepatitis $C$ virus and human immunodeficiency virus in Northern Cyprus. BTDMJB. 2018;14:332-338. [CrossRef] 